\title{
LAS LEYENDAS MODERNAS Y LA TRANSMISIÓN DE VALORES
}

\author{
José Manuel DE PRADA SAMPER \\ Escritor e investigador \\ jmd194@columbia.edu
}

Resumen: Las leyendas modernas reflejan los miedos y preocupaciones de la sociedad contemporánea. Aunque algunas de ellas pueden suscitar episodios violentos de histeria colectiva, otras, como cualquier forma de relato, transmiten valores y conocimientos fundamentales.

Abstract: Modern legends reflect the fears and preoccupations of contemporary society. Although some of them may provoke violent episodes of collective histery, others, like any form of narrative, can transmit essential values and knowledge.

Palabras clave: Leyendas. Modernas. Narración. Contexto. Ética.

Key words: Legends. Modern. Storytelling. Context. Ethics. 
Escuché por primera vez la leyenda de la autoestopista fantasma cuando tenía unos diez años, de boca de Elisenda que era una excelente narradora, menos por su forma de contar historias que por la amplitud y variedad de su repertorio, en el que abundaban las historias truculentas y con elementos sobrenaturales. La historia de la autoestopista me impresionó especialmente, quizá porque por aquel entonces yo viajaba mucho en coche con mi familia, y sentía una inquietud considerable cuando pasábamos por trechos que, al menos a mí, me parecían peligrosos. Es por tanto posible que yo llegara a identificarme hasta cierto punto con aquella espectral muchacha, que con tanto conocimiento de causa y un celo que iba más allá de la muerte, advertía a los conductores incautos sobre la peligrosidad de un punto negro de la carretera.

No volví a saber nada nuevo de esa pobre alma en pena hasta pasados doce años, cuando, en agosto de 1981, me topé con su asombrosa historia en uno de los artículos semanales que Gabriel García Márquez publicaba entonces en el periódico El País y de los que yo era un verdadero adicto. Cuando leí aquel artículo, titulado «Fantasmas de carreteras», sentí un escalofrío, no por el relato mismo, que yo había recontado ya infinidad de veces y había pasado a formar parte de mi ser, sino por el hecho de encontrar precisamente ahí, en el artículo semanal de Gabo, una historia que yo estaba convencido de que no podía conocer mucha gente. ¿No había dicho Elisenda que aquella aventura les había sucedido a unos conocidos de unos amigos de sus padres? Sin embargo ahí estaba, en una versión que, en los detalles esenciales, coincidía con la que a mí me era tan familiar. ¿Por qué extraños vericuetos había llegado hasta el escritor colombiano? Todo aquello me parecía inexplicable, y eso que, hacia el final del artículo, el propio García Márquez daba la clave de cómo se difunden esas historias:

[Los conductores] profesionales — como los arrieros de mulas-son fuentes infinitas de relatos fantásticos. En las fondas de carreteras, como en las ventas antiguas de los caminos de herradura, los camioneros curtidos, que no parecen creer en nada, relatan sin descanso los episodios sobrenaturales de su oficio, sobre todo los que ocurren a pleno sol, y aún en los tramos más concurridos (García Márquez, 1981: 7; 1991: 145-146).

Aquello tendría que haberme aclarado todo, pero lo cierto que no sirvió para sacarme de mi perplejidad. En aquel entonces eran autores como Joyce, Kafka o Canetti los que acaparaban por completo mi entusiasmo literario, y apenas era consciente de la existencia de la tradición oral. A pesar de esto, las historias transmitidas de viva voz eran importantes para mí, aunque yo no 
fuera consciente de ello. Esto no tiene nada de extraño. La mayor parte eran relatos sin pretensión artística alguna que había oído contar a menudo, y que estaban hasta tal punto integrados en el tejido de mi existencia que no se hacían notar, aunque, de una forma silenciosa, actuaran dentro de mí. Eran las anécdotas que mi padre contaba sobre su infancia, o las historias de mi abuela sobre los tiempos de la guerra civil; también, por supuesto, las leyendas truculentas que con el pasar de los años había oído contar a Elisenda y a otras personas sobre niñeras drogadas que meten en el horno a los bebés a su cargo, o estudiantes de medicina cuyas bromas macabras terminan en tragedia.

Antes de continuar es mejor que definamos qué es una leyenda, y aclaremos una cuestión de terminología respecto a las llamadas leyendas urbanas. A grandes rasgos, una leyenda es un relato tradicional, transmitido oralmente, que es considerado cierto por el narrador y por gran parte de su público, pero que contiene elementos sobrenaturales o fuera de lo común. Por supuesto, hoy en día, existen otros vehículos para la transmisión de leyendas, el más importante de los cuales, y que ha generado sus propias tradiciones, es Internet. Precisamente porque las leyendas de las que estamos hablando se cuentan en todas partes, y no sólo en las ciudades y llegan así a todos los lugares, estoy de acuerdo con otros folkloristas en que la mejor forma de referirse a ella es como leyendas modernas, y así me referiré a ellas en adelante ${ }^{1}$.

Volviendo al tema del contexto y los narradores, para entender la pasión que algunos folkloristas sentimos por informarnos sobre las personas que cuentan relatos, y las circunstancias en que lo hacen, vale la pena citar el siguiente pasaje de la obra de John Niles, Homo Narrans:

La atención que los estudiosos prestan a los factores contextuales que afectan profundamente la naturaleza de las manifestaciones culturales [...] es algo más que una moda pasajera parecida al furor que hubo en su día por encontrar ramas doradas. [Los factores contextuales son] un requisito previo para entender la poética de la narración oral. En cada eslabón de la cadena de transmisión hay un ser humano. Los [...] narradores de historias optan por añadir sólo ciertos materiales a su repertorio e, inevitablemente, recrean dichos materiales en función de su estilo personal y de su mentalidad y en función de la respuesta que esperan del público (Niles, 1999: 156).

1 Para otras opiniones sobre el concepto de leyenda urbana, y sobre la naturaleza de este género, véanse los importantes trabajos de José Manuel Pedrosa (2002 y 2004) y Josep M. Pujol (2002). 
Por otro lado, la folklorista húngara Linda Dégh, que fue la gran impulsora del método sociocultural en el estudio del folklore, dice a propósito de los narradores de leyendas:

Los narradores de leyendas no existen en el mismo sentido que los narradores de cuentos, los cantores de epopeyas [u otros transmisores de la tradición.] Ellos no disponen de un escenario [habitual] ni hay un reconocimiento social para su habilidad narrativa. La leyenda no es considerada como un arte de inspiración personal que se ejerce para disfrute de un público atento, sino como un área concreta de conocimiento sobre la que el narrador puede aportar información. No es la historia lo que cuenta, sino el mensaje que transmite. El mensaje da forma a la historia para que tenga sentido y capte el interés (Dégh, 1995: 79).

Existen, sin embargo, unas reglas elementales que todo narrador de leyendas que se precie debe tener en cuenta si quiere que el mensaje se transmita adecuadamente. A grandes rasgos, estas reglas son las siguientes:

- El narrador refiere el relato como un suceso verdadero, de forma que da toda clase de detalles circunstanciales que sirvan para reforzar su verosimilitud. En el caso de la versión que da García Márquez de «La autostopista fantasma»: «Dos muchachos y dos muchachas que viajaban en un Renault 5, recogieron a una mujer vestida de blanco [...] que viajó en silencio varios kilómetros, sentada en el asiento posterior, hasta un poco antes del puente de Quatre Canaux».

- El narrador proporciona también detalles precisos sobre el momento en que tuvo lugar la historia: «Esto ocurrió el 20 de mayo, en la carretera de París a Montpellier», dice García Márquez.

- Otro recurso del narrador de leyendas es atribuir la aventura o suceso a un familiar o un conocido o, en su defecto, citar una fuente irrefutable, como pueda ser una publicación de renombre o un conocido canal de televisión. García Márquez no cita una fuente concreta, pero dice «casi toda la prensa de Francia lo comentó en los días siguientes».

Atenerse a estas reglas contribuye a que una leyenda, si está bien contada, sea, ante todo, un relato plausible. En el verano de 2003 recogí en varias zonas de la comunidad de Castilla y León relatos sobre moras que viven en el interior de ciertas peñas, donde custodian tesoros escondidos. A menudo, mis informantes no descartaban que pudiera haber algo de cierto en estas histo- 
rias y, de hecho, se ceñían a las reglas que acabo de mencionar, y me indicaban de forma aproximada cuándo tal persona encontró un tesoro escondido en tal sitio, etc. Sin embargo, quienes hayan vivido en una gran ciudad la mayor parte de su vida, tenderán a considerar de entrada estas tradiciones como relatos ficticios, aunque por otro lado den crédito a los rumores sobre cocodrilos en las alcantarillas o platillos volantes.

Las leyendas modernas reflejan una forma de ver el mundo y unas preocupaciones en gran medida diferentes a las que se aprecian en los relatos que ya se contaban hace un siglo, pero se narran siguiendo las mismas reglas destinadas a dotarlas de verosimilitud. La cosmovisión que reflejan está, inevitablemente, marcada por el entorno urbano, y por el obligado anonimato que las grandes ciudades imponen a sus habitantes. En su contenido podemos también detectar las preocupaciones, miedos y esperanzas del hombre moderno, en especial ese sentimiento de incertidumbre y desarraigo visible sobre todo en las generaciones más jóvenes. Como se ha dicho con frecuencia, algunas leyendas modernas plasman nuestro desasosiego ante el lado más oscuro de los avances tecnológicos que, por otra parte, nos facilitan la vida. Así, el avión, el microondas, el ordenador, y muchos otros inventos desempeñan un importante papel en no pocas de las historias más difundidas. Otras leyendas, de las que no se habla tanto pero que también están muy extendidas, se caracterizan por expresar la inquietud que en nosotros despierta el contacto cotidiano con personas de culturas muy distintas a la nuestra, a veces con una crítica implícita a nuestros propios hábitos y costumbres. Ahí está, por ejemplo, la conocida tradición sobre un niño muy pequeño cuyos padres, altos ejecutivos, se desesperan porque creen que no aprende a hablar, hasta que el pediatra les dice que el niño sí que habla, pero sólo en tagalo, la lengua de su niñera filipina, con la que pasa más tiempo que con sus atareados progenitores. Otras historias son menos benévolas con los extranjeros, como atestigua la también muy extendida creencia de que, con el fin de aprovechar su pasaporte y demás documentos, los chinos reciclan a sus difuntos introduciéndolos en la cadena alimentaria a través de sus ubicuos restaurantes.

Relatos de este tipo llevan a mucha gente a decir que las leyendas modernas son por regla general xenófobas y racistas. Esto es, cuanto menos, exagerado, puesto que la mayor parte de las leyendas nada tienen que ver con estas cuestiones. De las que sí tienen que ver, algunas son realmente calumniosas. Otras pueden o no serlo: todo depende del contexto y la finalidad con que se narren. Aun así, es un hecho que la demonización del Otro atribuyéndole las conductas más abominables es una práctica tan antigua como la 
propia fragmentación de la especie humana, una práctica que a menudo ha servido para apuntalar toda clase de teorías conspiratorias, o para deshumanizar a quienes, dentro o fuera de las propias fronteras, eran tenidos por enemigos.

Así, en la Edad Media, el rumor de que los judíos secuestraban a niños para sacrificarlos en los rituales de la Pascua contribuyó en gran medida al sufrimiento y la muerte de miles de inocentes. En su origen, el rumor en cuestión fue quizá fruto del miedo y la ignorancia de las capas más humildes de la población cristiana. Pero su cristalización en una serie de leyendas perfectamente estructuradas, es con toda seguridad el resultado de su manipulación a manos de las altas esferas políticas y eclesiásticas, interesadas, cada una por distintos motivos, en la destrucción y expolio de las comunidades judías. Algunas de estas leyendas seguían vivas hasta no hace mucho en la tradición oral de muchos lugares en forma de relato o de balada. En España, donde no me consta la existencia de versiones orales, la calumnia de la sangre aparece incluso en algunos catecismos de la posguerra. No sería difícil encontrar otros ejemplos de este tipo de intoxicaciones, que muestran el lado más oscuro de las capacidades fabuladoras del ser humano ${ }^{2}$. En cualquier caso, no es necesario retroceder tanto en el tiempo para constatar la fuerza de sugestión que pueden llegar a tener estos rumores, antes y después de transformarse en relatos más o menos estructurados.

En mayo del año 2000, los medios de comunicación informaron que un turista japonés y un chófer local habían sido asesinados por una turba de campesinos enfurecidos en el pueblo guatemalteco de Todos Santos $\mathrm{Cu}$ chumatán, cuya población es mayoritariamente de etnia maya. Sobre este terrible episodio se publicaron numerosas noticias en la prensa, pero prefiero citar aquí un extracto de informe sobre violación de derechos humanos elaborado por la misión de las Naciones Unidas en Guatemala, que aborda este y otros casos de linchamiento:

Diversas informaciones indican que desde comienzos de abril habían circulado rumores en Todos Santos Cuchumatán sobre un supuesto cónclave de «maras» [pandillas] provenientes de diversos puntos del país e inclusive del extranjero, que se reunirían en la cabecera departamental con el objeto de celebrar ritos satánicos que incluirían el sacrificio de niños. Agregaban que los integrantes de las maras [pandillas] se movilizarían en un bus grande y ves-

\footnotetext{
2 Sobre la calumnia de la sangre y sus variantes más recientes, véase Brunvand (1986: 78-92).
} 
tirían de negro. Autoridades locales, radios y grupos religiosos habrían difundido el rumor, fomentando un estado de zozobra (MINUGUA, 2001: 35).

Otras interpretaciones del hecho, entre ellas la contenida en un comunicado de prensa de la embajada estadounidense en Honduras (citado por el diario El Tiempo de Tegucigalpa, 11 de mayo, 2000) sugieren que los aldeanos creían que los turistas japoneses pretendían raptar a los niños para robarles los órganos. En ambos casos, ritos satánicos y robo de órganos, se trata de leyendas difundidas en todo el mundo. Obsérvese que, según el informe de MINUGUA, las autoridades y medios de comunicación lejos de disipar el rumor, contribuyeron a su difusión.

Otro ejemplo procede de una noticia de prensa publicada el 14 de enero de 2003 en el periódico The New York Times. En este artículo, elaborado sobre el terreno por Rachel L. Swarns, se dice que la población de Blantyre, en Malawi, un país del África occidental, vivía entonces presa de la histeria ante la convicción de que hombres vestidos de negro y provistos con linternas y jeringuillas asaltaban a los caminantes y, después de reducirlos con un gas adormecedor, les robaban la sangre. Debilitadas, las víctimas terminaban por morir. El gobierno desmintió estos rumores de forma insistente, pero en vano:

En las aterradas aldeas las opiniones del gobierno son descartadas. El debate gira sobre todo en torno a si los chupadores de sangre son espíritus o seres humanos con poderes mágicos. Nadie pone en duda que los vampiros son reales.

Y, más adelante, se cita este testimonio de una testigo:

Ha estado sucediendo casi cada semana [...] Los hemos visto, pero no nos hemos acercado. Llevaban ropas negras y siempre caminaban deprisa. He oído en la radio el comunicado del gobierno, pero nosotros sabemos lo que está pasando (Swarns, 2003: ed. el.).

La autora del artículo ofrece varias teorías plausibles para explicar la histeria de los campesinos de Blantyre: la terrible hambruna que azota la región de un tiempo a esta parte, la pobreza, las creencias ancestrales de los aldeanos... De todas estas explicaciones, la que a mí me parece más convincente, es ésta: «Una vez más, el sida puede tener la culpa. La vergüenza y el estigma que rodean la enfermedad son tales que mucha gente quizá prefiera echar a los vampiros la culpa del mal y de las muertes que causa» (Swarns, 2003: ed. el.). 
También aquí los rumores tuvieron consecuencias trágicas. En una noticia fechada el 8 de febrero de 2003, el periódico en línea Malawi Here informa de que «desde que comenzaron estos rumores, los aterrados aldeanos han matado a golpes a dos hombres sospechosos de ser vampiros, han atacado y casi linchado a tres sacerdotes que visitaban el lugar y han destruido el campamento de un grupo de cooperantes que pasaba por ser el centro de operaciones de los vampiros» (ed. el.). Obsérvese el detalle de que, como en Guatemala, también aquí los malvados intrusos visten de negro. No obstante, en este caso está claro que el gobierno desmintió categóricamente los rumores e hizo todo lo posible por detener su propagación.

Sin embargo, no hace falta que nos vayamos tan lejos para encontrar ejemplos de la fuerza de estas historias. Cuando en marzo de 2002 se celebró en Barcelona una importante cumbre de la Unión Europea, muchas empresas de la zona alta de la ciudad prefirieron cerrar sus puertas durante los dos días en que tuvieron lugar las reuniones. El motivo: poco antes de la celebración de la cumbre circuló con insistencia en Barcelona la leyenda, que podríamos llamar del terrorista bueno, según la cual una persona, en general una mujer, que acababa de prestar un euro a un hombre de aspecto magrebí para que pudiera comprarse un billete de metro, recibió de éste, en pago por su amabilidad, la siguiente advertencia: «Señora, por haber sido usted tan buena conmigo, le voy a dar un consejo: el día de la cumbre, no utilice usted los transportes públicos, porque va a suceder algo grave».

En un primer momento yo pensé que esta leyenda había surgido como resultado de los temores despertados por la cumbre, cuya celebración en Barcelona era conocida desde hacía tiempo y había dado lugar a un aparatoso despliegue policial. Sin embargo, supe poco después por Antonio Ortí, que es un experto en la materia, que hacía por lo menos un año que circulaba la historia de una señora que recibe una advertencia similar de un joven al que ha prestado un euro para poder sacar un carrito de la compra en una sucursal de Eroski, situada en las afueras de Bilbao.

Todo lo que hemos dicho hasta ahora sugiere que el género de la leyenda, comparado con otras formas de arte verbal, ocupa un lugar ambiguo y a menudo incómodo, sobre todo por su estrecha asociación con categorías tan cuestionables y tan poco literarias como son el rumor, la superstición o la propaganda. A pesar de esto, hay que insistir en que la leyenda, aun siendo un género relativamente menor, es tan honroso y respetable, como, pongamos, el mito o el cuento de magia. Por otro lado, está demostrado que estos géneros, con los que a menudo la leyenda se solapa y a los que a veces sirve 
de fuente, pueden ser también portadores de calumnias e invitaciones al odio. En realidad, como cualquier otra manifestación de la capacidad narrativa del ser humano, la leyenda, aun en su forma más humilde y afín al simple rumor, puede desempeñar una de las funciones principales de toda forma de creación artística: la transmisión de un individuo a otro, y de una generación a la siguiente, incluso en las circunstancias más difíciles y precarias, de valores y conocimientos fundamentales ${ }^{3}$. Como ejemplo de esto, quisiera citar ahora, y comentar con cierto detenimiento, una leyenda moderna que nos llega de uno de los periodos más siniestros de la historia reciente de la humanidad, y que creo puede servir para al menos ilustrar someramente algunas de las últimas cuestiones que he sacado a colación.

El relato al que me refiero nos ha sido transmitido por Victor Klemperer, un filólogo alemán que, tras subida de Hitler al poder, fue expulsado de su puesto de profesor de literatura en la Universidad de Dresde y privado de sus derechos civiles por el hecho de ser judío. A diferencia de muchos otros intelectuales alemanes de la época, judíos y no judíos, Klemperer optó por no exiliarse, y seguía en Alemania cuando estalló la Segunda Guerra Mundial. Al final, si Klemperer se salvó de la cámara de gas fue gracias al hecho de estar casado con una mujer aria que resistió todas las presiones del régimen para que se divorciara de su marido. A pesar del terrible acoso cotidiano al que él y su esposa estaban sometidos, Victor Klemperer conservó la lucidez y, aunque ello representaba un peligro considerable, no interrumpió la redacción de su diario, que hoy día constituye un insustituible testimonio sobre lo que era vivir en condición de apestado en el corazón mismo de la Alemania nazi. Además de esto, el filólogo hizo un importante esfuerzo para documentar en ese mismo diario los usos lingüísticos que fueron implantándose durante el III Reich como resultado del esfuerzo del régimen por imponer a la población una forma única de pensar. Fruto de esta investigación es el fascinante y muy recomendable libro LTI: Apuntes de un filólogo, que se publicó por primera vez en 1947. De él procede el extracto que cito a continuación, aunque algunos de los datos los tomo de la reciente traducción castellana de los propios diarios (Klemperer, 2003).

Antes de pasar al relato mismo, es necesario señalar que Klemperer, con rigor de folklorista, proporciona a sus lectores abundante información sobre sus fuentes. Así, nos dice que el relato lo escuchó no mucho antes del estallido de la guerra, de boca del señor Vogel, un comerciante de la zona baja de

3 Sobre esta función de los relatos, véase Biesele (1993: 53-62). 
Dresde que seguía suministrándoles provisiones a él y a su esposa en un momento en que, dice el filólogo, «ya estábamos muy aislados y vigilados, y se necesitaba bastante valor para visitarnos» (Klemperer, 2001: 99). Sobre el señor Vogel dice Klemperer que era un hombre no demasiado culto, que «todo lo veía desde la perspectiva de lo cotidiano y del sentido práctico» (ibid.), y no tenía un especial interés por la religión. Tampoco era un hombre interesado en política, pero «lo indignaban la evidente corrupción, injusticia y tiranía del nacionalsocialismo» (ibid.). Klemperer destaca también otros dos rasgos del señor Vogel: que no se dejaba «embriagar por los tópicos y mentiras del gobierno» (ibid.) a diferencia de decenas de miles de comerciantes pequeñoburgueses como él, y que era un «hombre sensato, protestante para más señas, es decir, sin una infancia impregnada de historias de santos y de mártires» (Klemperer, 2001: 100). En su Diario, Klemperer añade dos detalles que son de interés: uno, que Vogel le contó la historia con toda seriedad $\mathrm{y}$ «lleno de pavor» y otro, que el relato circulaba «clandestinamente porque propagarlo se castiga con la cárcel» (Klemperer, 2003: vol. I, 420).

La historia dice lo siguiente:

Un Obersturmführer [teniente coronel de los escuadrones de asalto] de las SS, en Halle o en Jena —el tendero proporcionó una información muy precisa sobre el lugar y las personas, pues todo le había sido comunicado «con todas las garantías» por «fuentes absolutamente fiables»-, un alto oficial de las SS, pues, había llevado a su mujer a una clínica privada para el parto. Echó un vistazo a la habitación; sobre la cama colgaba una imagen de Jesucristo.

- Quite de ahí ese cuadro - exigió a la enfermera-, no quiero que lo primero que vea mi hijo sea un judío.

La monja, temerosa, dio una respuesta evasiva, señalando que ya se lo diría a la madre superiora. El hombre de las SS se marchó, no sin antes repetir la orden. A la mañana siguiente, la madre superiora lo llamó por teléfono:

-Tiene usted un hijo, señor Obersturmführer, su esposa se encuentra bien, y el niño también es robusto. Además, se ha cumplido su deseo: el niño nació ciego... (Klemperer, 2001: 99-100) .

${ }^{4}$ Hay que decir que la versión del diario (Klemperer, 2003: vol. I, 420) omite varios detalles de la que se publicó en $L T I$. Por ejemplo, en el diario se habla simplemente de «un hombre», y no de un oficial de las SS. Dada la precaria y peligrosa situación en que vivía cuando redactaba su diario, lo más probable es que Klemperer omitiera los detalles por prudencia o economía, pero que éstos formaran parte del relato tal y como se lo contó Vogel. 
Este relato, que es mucho menos sencillo de lo que pueda parecer a simple vista, se desarrolla en torno a una variante del motivo folklórico internacional, catalogado por Stith Thompson con el número Q 451.7.02, «ceguera milagrosa impuesta como castigo». También podrían traerse a colación otros dos motivos de amplia difusión: el Q 338, «petición desmesurada castigada» y el J 2072, «deseo corto de miras». En suma, como tantas otras leyendas, el relato del que hablamos reelabora elementos tradicionales que llevaban mucho tiempo en circulación.

La leyenda, que es de indudable origen católico, nos muestra la profunda incompatibilidad entre el pensamiento cristiano y algunos de los dogmas fundamentales de la doctrina nacionalsocialista. El teniente coronel de las SS es un nazi entusiasta y bien adoctrinado, como deja ver el hecho de que, de forma tajante, ordene a la enfermera que retire la imagen ofensiva. La enfermera no se pliega dócilmente a las exigencias del militar. El relato nos dice que se muestra «temerosa», aunque no queda claro si a causa del SS o por escrúpulos religiosos. Lo cierto, sin embargo, es que logra eludir el acatamiento de la orden remitiéndose a una autoridad superior. El teniente coronel considera que ahí no hay más autoridad que la suya, y repite la orden antes de marcharse. Al día siguiente, la autoridad superior a la que ha apelado la enfermera explica al militar de qué modo se ha cumplido su deseo. De esto se desprende que, después de todo, la orden del SS no llegó a cumplirse, y la imagen jamás fue retirada.

Podemos imaginar que el público católico de este relato veía en él un ejemplo edificante de cómo Dios castiga a los soberbios cuándo y cómo menos se lo esperan. El régimen es una afrenta a la divinidad, pero ésta no ha desamparado a los hombres, e interviene en favor de los justos, aunque lo haga siguiendo caminos inescrutables. Para el creyente, éste es, quizá, el mensaje más evidente de la leyenda. Es un mensaje de consuelo y de esperanza basado en la fe religiosa.

Pero en el relato hay más. Así, llama la atención que el SS exprese su rechazo a la imagen porque en ésta ve «a un judío». La doctrina oficial del nazismo negaba que Jesús fuese judío y daba toda una serie de pintorescos argumentos para afirmar su carácter ario. En principio, pues, la imagen de Jesús no tendría por qué ofender al futuro padre. Sabemos, sin embargo, que Hitler creía que estaba llamado a terminar la misión que Cristo inició en la Tierra, aunque al plantear esto no se identificaba con el Cristo crucificado, sino con el Cristo airado que expulsó a los mercaderes judíos del Templo (Rosa Sala, 2003: 218-224). Quizá lo que ofende al SS es que la imagen 
muestra a un hombre torturado y derrotado. Pero no, lo que más molesta al oficial no es eso. El relato dice explícitamente que la imagen le resulta ofensiva, por mostrar a «un judío». Esto introduce en la leyenda un claro rechazo a los planteamientos raciales del régimen y la proyecta más allá del ámbito católico. El SS es castigado no sólo por ser anticristiano, sino también por ser antisemita. Y el castigo es en verdad terrible, pues para un hombre que abraza con todas sus consecuencias una ideología que proclama la necesidad de eliminar a cuantos padezcan defectos físicos que contaminen la raza aria no puede haber desgracia mayor que tener un hijo ciego. No sólo porque, por usar las palabras de Hitler en el Mein Kampf, traer al mundo a un ser «enfermizo y débil» era una «lamentable desgracia» y una «deshonra» (Hitler, s.a), sino porque para el oficial era casi una obligación sacrificar personalmente a su hijo en virtud del epígrafe llamado Acción 14, nombre encubierto de las tareas de eugenesia que el régimen practicó de forma bastante abierta hasta 1941. El relato es así algo más que una expresión de piedad cristiana. Su mensaje es subversivo a muchos niveles, más de los que aquí he esbozado. No es de extrañar que Vogel considerase que la historia podía ser de interés para su amigo, el profesor judío.

El 27 de diciembre de 1943, al referir en su diario otra leyenda, ésta puramente judía, Klemperer se asombra de la credulidad de quien se la cuenta:

En 1938, los judios de Leipzig fueron sacados de la cama a las 4:15 horas y llevados al campo de concentración; a las 4:15 horas atacaron el otro día los ingleses y todos los relojes eléctricos quedaron parados en las 4:15 (Klemperer, 2003: vol. II, 469).

Tanto en LTI como en los diarios, Klemperer trata estos relatos con cierta condescendencia, y parece considerarlos una curiosa forma de reversión a una mentalidad primitiva en un periodo de crisis. Sin embargo, para quienes, como el propio Klemperer, vivían sometidos a la amenaza constante de cualquier día ser deportados a un campo de exterminio, y tenían a diario que enfrentarse a todo tipo de humillaciones, vejados e insultados por las calles, sometidos a la constante vigilancia de los esbirros de la Gestapo, que les golpeaban y robaban cuando les venía en gana, para la inmensa mayoría de quienes vivían en semejante situación, este tipo de relatos tenía por fuerza que ser una fuente de esperanza y un estímulo para seguir adelante. No así para Klemperer, hombre de una gran cultura, que derivaba esas energías de la lectura de los libros que, cada vez con mayores dificultades, podía procurarse, y de las diversas actividades intelectuales y creativas a las que se entre- 
gaba siempre que le era posible, entre ellas la redacción de una historia de la literatura francesa del siglo XVIII.

Klemperer nos dice que eran muchas las leyendas de este tipo que circularon durante el III Reich. El régimen, por supuesto, era consciente de ello. En una anotación de junio de 1943, el filólogo refiere que en la ciudad de Dresde se veía entonces un cartel que mostraba a dos personas diciéndose algo al oído y la inscripción: «Quien cuchichea, miente»:

Caigo ahora en la cuenta de que ya se viene escribiendo hace tiempo, hace mucho tiempo, contra la propaganda del cuchicheo. Y que «propaganda del cuchicheo» es una expresión característica [del lenguaje nazi] que, indudablemente, tiende a fomentar la mala conciencia y trae a la memoria las penas de reclusión mayor "para quienes escuchan radio extranjera» (Klemperer, 2003: vol. II, 390).

Pero las puertas de la imaginación son imposibles de cerrar. Es muy improbable que el régimen nazi hubiera jamás conseguido acallar los cuchicheos que, poco a poco, socavaban su autoridad. En muchos casos, es cierto que los rumores eran mentiras. A diferencia de la propaganda y la mitología del régimen, sin embargo, las mentiras de muchos de estos molestos cuchicheos eran una forma de expresar verdades que, a causa de la censura y la represión, era imposible comunicar por otros caminos. Es decir, no eran falsedades, sino ejercicios de la imaginación o, si se quiere mentiras verdaderas. Por ceñirnos al ejemplo que hemos estado comentando, sin duda ningún SS tuvo un hijo ciego en una clínica privada en la que se había desobedecido la orden de retirar una imagen de Jesucristo. El SS, su mujer embarazada, la enfermera y la madre superiora son personajes de ficción, pero personajes verosímiles, que representan a instituciones y actitudes reales y a través de los cuales se articulan de forma clara planteamientos que responden a la verdad.

Los nazis pretendían desmantelar por completo el antiguo sistema de valores, que les parecía decadente y más propio de gentes débiles que de un pueblo llamado a conquistar el mundo. Sin embargo, la difusión de leyendas como la recogida por Klemperer demuestra que, al tiempo que los grandes jerarcas del régimen dinamitaban por un lado los valores tradicionales, éstos se atrincheraban allí donde siempre lo han hecho con ocasión de crisis parecidas: en la literatura no escrita de las capas más humildes de la población. Klemperer nos dice que estos relatos «provenían siempre de gente humilde, trabajadores, vagabundos, carteros confiados y, por tanto, imprudentes» (2001: 98). Ellos las originaban, quizá, pero personas más acomodadas y pru- 
dentes, como el tendero Vogel, les prestaban atención y no dudaban en sumarse a la cadena de transmisión, a pesar del riesgo muy real que entrañaba propagar este tipo de historias en la Alemania nazi. Vogel, como se nos dice, era un hombre con poca cultura y sin ninguna amplitud de intereses, pero que jamás se dejó engañar por la propaganda del régimen. Lo más esperanzador del relato recogido por Klemperer es que llegara siquiera a existir en medio de todo aquel horror, y fuese transmitido de católico a protestante, de protestante a judío, por gente como Vogel. Incluso si Hitler hubiera ganado la guerra, es harto dudoso que su Reich hubiese durado mil años, porque ni con las medidas más drásticas y brutales hubiera podido acallar los rumores y las historias subversivas y desmantelar por completo el viejo sistema de valores. Al cabo de dos o tres generaciones, si no antes, éste hubiera iniciado su lento pero imparable retorno.

Un rasgo llamativo de los diversos ejemplos que he citado de leyendas modernas y sus efectos y consecuencias, es que, tanto en Guatemala, como en Malawi, como en Barcelona, como en la Alemania nazi, los relatos, rumores, o como quiera que se los llame, surgen en gran medida del miedo. Sin embargo, la historia del oficial que tiene un hijo ciego deja claro que la imaginación y sus frutos sirven para algo más que adormecer la razón y liberar monstruos. Los relatos que creamos y transformamos con nuestra imaginación, además de transmitir los valores necesarios para la continuidad de nuestra especie, nos ayudan también a la tarea constante de construir y actualizar el complejo entramado cultural que engloba esos valores y sin el cual la vida en sociedad sería imposible.

A diferencia de lo que muchos folkloristas creen, el mundo moderno, con sus grandes aglomeraciones y sus medios de comunicación de masas, no ha acabado con la tradición oral, porque ésta es indestructible, pero sí ha contribuido a la atrofia de algunos de los géneros mayores de la literatura tradicional. El futuro de esos géneros es incierto, pero sería muy prematuro extender su certificado de defunción. La leyenda, sin embargo, ha prosperado, y quizá goce de mejor salud que nunca. Eso se debe en gran medida a que, como hemos visto, se trata de un género apegado fundamentalmente al aquí y al ahora. No sólo no está nunca lejana en el tiempo ni el espacio, sino que jamás se separa de nosotros, porque contar y escuchar esas historias responde a una necesidad vital. En la mayor parte de las sociedades, la narración de los mitos y los cuentos suele ser el dominio de personas especialmente dotadas para contarlos, en ocasiones de verdaderos profesionales. La leyenda, en cambio, se deja contar por cualquiera, y encuentra su cauce natural no en los recitales formalizados, sino en las conversaciones relajadas e informales 
que para cualquiera de nosotros son un rasgo irrenunciable de la existencia cotidiana porque sin ellas no podríamos vivir.

«La lógica es sin duda inconmovible - dice Franz Kafka al final de $E l$ proceso - pero no resiste a un hombre que quiere vivir» (2003: 213). El camino seguido hasta ahora por la humanidad parece responder a una lógica implacable, una lógica que sólo puede terminar con la total aniquilación de esa increíble constelación de culturas y sensibilidades que hemos sabido crear durante milenios en cualquier punto del planeta donde el ser humano haya sido capaz de aclimatarse y prosperar. Con todo, nuestra voluntad de vivir no desfallece, y esa obstinación invita a pensar que, al fin y al cabo, no todo está perdido y que, además del camino de la nada, hay otro, igualmente practicable, que lleva hacia la cordura y la vida. Quizá debería consolarnos el hecho, cualquiera que sea el camino que finalmente tomemos, de que los relatos que hemos ido creando durante milenios, se trate de las sofisticadas epopeyas cantadas por los bardos de Mesopotamia y Grecia, o las modestas historias de fantasmas oídas en la niñez durante una tarde lluviosa, nos acompañarán hasta el final.

\section{REFERENCIAS BIBLIOGRÁFICAS}

BIESELE, M. (1993). Women Like Meat: The Folklore and Foraging Ideology of the Kalahari Ju/' hoan. Bloomington e Indianapolis: Witwatersrand University Press-Indiana University Press.

Brunvand, J. H. (1981). The Vanishing Hitchhiker: American Urban Legends and Their Meanings. Nueva York: W. W. Norton.

— (1986). The Choking Doberman and Other «New» Urban Legends. Nueva York: W. W. Norton.

DÉGH, L. (1995). Narratives in Society: A Performer-Centered Study of Narration. Folklore Fellows Communications n. ${ }^{\circ} 225$. Helsinki: Academia Scientiarum Fennica.

El Tiempo (2001). «Técnicamente es imposible el tráfico de órganos humanos». El Tiempo, Tegucigalpa, 11 de mayo, edición electrónica, http://www.tiempo.hn/.

García Márquez, G. (1981). «Fantasmas de carreteras». El País, 19 de agosto, 7 . 
— (1991). Notas de prensa 1980-1984. Barcelona: Mondadori.

Hitler, A. (s.f.). Mi lucha, traducción de Alberto Saldívar. Santiago de Chile: Ediciones Más Allá.

KAFKA, F. (2003). El proceso, traducción de Miguel Sáenz. Barcelona: DeBolsillo.

Klemperer, V. (2001). LTI: Apuntes de un filólogo, traducción de Adán Kovacsics. Barcelona: Minúscula.

- (2003). Quiero dar testimonio hasta el final: Diarios 1933-1945, traducción de Carmen Gauger, 2 vols. Barcelona: Galaxia Gutenberg.

Malawi Here (2003). «Malawi Vampire Stories Refuse to Die». Malawi Here, 8 de febrero, edición electrónica, www.malawihere.com.

Minugua (2001). Suplemento al duodécimo informe sobre derechos humanos de la misión de verificación de las Naciones Unidas en Guatemala, Guatemala, septiembre.

NiLEs, J. (1999). Homo Narrans: The Poetics and Anthropology of Oral Literature. Filadelfia: University of Pennsylvania Press.

Pedrosa, J. M. (2002). La ciudad oral: Literatura tradicional urbana del sur del Madrid. Madrid: Comunidad de Madrid, Consejería de Educación.

- (2004). La autoestopista fantasma y otras leyendas urbanas españolas. Madrid: Páginas de Espuma.

Pujol, J. M. (coord.) (2002). «Benvingut/da al club de la sida» i altres rumors d'actualitat. Barcelona: Generalitat de Catalunya, Departament de Cultura.

Sala Rose, R. (2003). Diccionario crítico de símbolos y mitos de nazismo. Barcelona: El Acantilado.

Swarns, R. L. (2003). «Blantyre Journal: Not Your Usual Vampires, but Scary Nonetheless». The New York Times, 14 de enero, edición electrónica, http://www.nytimes.com/.

Thompson, S. (1975). Motif-Index of Folk Literature, edición revisada y aumentada, 6 vols. Bloomington y Londres: Indiana University Press. 